\title{
Load sharing model for high contact ratio spur gears with long profile modifications
}

\author{
José I. Pedrero' ${ }^{1}$ D $\cdot$ Miguel Pleguezuelos $^{1}$ (D) - Miryam B. Sánchez ${ }^{1}$ (D)
}

Received: 28 March 2019 / Accepted: 8 June 2019

(c) The Author(s) 2019

\begin{abstract}
The start of contact between loaded involute gear teeth occurs before reaching the theoretical inner point of contact due to the load-induced deflections of previous tooth pairs in contact. This sooner contact occurs outside the pressure line and produces a shock between the driving tooth root and the driven tooth tip, which induces noise, vibrations and dynamic load. To avoid these undesirable effects profile modifications are often used, which through a suitable tip relief at the driven tooth delay the actual start of contact until locate it at the theoretical inner point of contact. However, the length and shape of profile modification have also influence on the curves of load sharing and quasi-static transmission error. Specifically, long tip relieves, beyond the interval of minimum tooth pair contact, which are unsuitable for standard contact ratio spur gears, may reduce drastically the load at the inner points of the path of contact of high contact ratio gears, though a peak of load arises at the outer interval of two pair tooth contact. Since the determinant contact stresses are usually located at the inner points of the contact interval and the determinant tooth-root stresses at the outer ones, long tip relieves can be used for balancing both determinant stresses and improving the load capacity.
\end{abstract}

Symbols

$b_{0} \quad$ Parameter for the approximation of meshing stiffens

$d_{\alpha} \quad$ Fractional part of contact ratio

F Load, N

$F_{T} \quad$ Total load, N

$K_{M} \quad$ Meshing stiffness, $\mathrm{N} / \mathrm{mm}$

$P_{F} \quad$ Bending load capacity, $\mathrm{W}$

$P_{H} \quad$ Pitting load capacity, W

$R \quad$ Load sharing ratio

$r_{b} \quad$ Base radius, $\mathrm{mm}$

$r_{c} \quad$ Contact point radius, $\mathrm{mm}$

$z \quad$ Number of teeth

$\alpha_{t}^{\prime} \quad$ Operating pressure angle

$\delta \quad$ Tooth pair deflection, $\mathrm{mm}$

$\delta_{G} \quad$ Approach distance inside the extended contact interval, mm
$\delta_{R} \quad$ Amount of relief, $\mathrm{mm}$

$\Delta \xi_{r} \quad$ Length of relief

$\varepsilon_{\alpha} \quad$ Contact ratio

$\varphi_{2} \quad$ Delay angle

$\xi \quad$ Involute profile parameter

$\sigma_{F} \quad$ Tooth root stress, $\mathrm{MPa}$

$\sigma_{H} \quad$ Contact stress, $\mathrm{MPa}$

$\xi_{\max } \quad$ Outer limit of the extended contact interval

$\xi_{\min } \quad$ Inner limit of the extended contact interval

\section{Subscripts}

c Contact point

inn Inner point of interval of contact

$m \quad$ Midpoint of interval of contact

$o \quad$ Outer point of interval of contact

$R \quad$ Relieved teeth

1 Driving gear

2 Driven gear

José I. Pedrero

jpedrero@ind.uned.es

Miguel Pleguezuelos

mpleguezuelos@ind.uned.es

Miryam B. Sánchez

msanchez@ind.uned.es

1 Departamento de Mecánica, UNED, Juan del

Rosal 12, 28040 Madrid, Spain

\section{Introduction}

The transmission error of a gear pair is defined as the difference between the actual and theoretical positions of the driven gear, for a given position of the driving gear [1]. One of the sources of transmission error is the flexibility of the teeth. The transmitted load induces deflections in the 
teeth, in such a way that the driving tooth tries to penetrate the driven tooth, resulting in a delay of the driven gear respect to the driving one [2]. This is the so-called quasistatic transmission error (QSTE).

Since the transmission error is not uniform along the path of contact, the output velocity oscillates along the meshing cycle, so dynamic loads and vibrations are unavoidably induced in the output shaft. In addition, the QSTE caused by the load, and the subsequent delay of the driven gear, results in a earlier start of contact of the next tooth pair, which occurs outside the pressure line and between non-conjugate contact points [2]. The root of the driving tooth hits the tip of the driven one, which provides longer effective contact interval but increases the noise, vibration and dynamic load levels. Previous studies on the load transfer along this extra contact interval reveal a parabolic loading process between actual and theoretical start of contact points [2,3]. A similar parabolic unloading process occurs at the end of contact [2].

To avoid this shock and its undesirable effects, profile modifications are often used. Indeed, a suitable tip relief at the driven tooth will move the start of contact to the theoretical location on the pressure line [2], providing a smoother transmission. A symmetric relief at the driving tooth tip will move the actual end of contact to the theoretical outer point of contact, though this profile modification is not as critical as the previous one because the parabolic unloading process induces a sudden disengage of meshing teeth but not a shock. Consequently, it is not unusual to modify the profile at the inner limit of the contact interval (i.e., at the driven tooth tip) but not at the outer limit (at the driving tooth tip).

The amount of material eliminated by profile modifications is very small (few microns in general) and has not significant influence on the stiffness of the tooth. However, the different contact conditions will affect the mesh stiffness of the couple of teeth, which will have influence on important transmission parameters, as the load sharing among couples of teeth in simultaneous contact or the transmission error $[2,3]$.

The influence of profile modifications on the meshing conditions has been investigated for many years. Last century, some studies on the influence of the amount, length and shape of profile modification on the dynamic load and transmission error were developed for both standard and high contact ratio spur gears $[4,5]$. More recently, the stiffness, the load sharing, and the transmission error have been studied by means of Finite Element techniques [6, 7]. Nowadays, the relations among meshing stiffness, transmission error, dynamic response and profile modification are still under the interest of researchers and manufacturers $[8$, 9], for which more accurate behavior models of gear teeth are essential to get improved and more efficient designs.
A tip relief is described by three parameters: the amount of modification, the length of modification and the shape of modification. The amount of modification is given by the teeth deflections of previous couples at the theoretical start of contact of the new pair, (i.e., the QSTE at the inner point of contact [2,3]), so it cannot be chosen by the designer. The shape of modification influences the load sharing between tooth pairs in contact, and consequently upsets the load sharing ratio (LSR) curve. The length of modification defines the interval of the meshing cycle in which the actual LSR curve differs from the theoretical one. For gear pairs with modified driven tooth tip but unmodified driving teeth, the shape of the tip relief governs the loading curve of the tooth pair at the start of contact, while the unloading curve at the end of contact is described by the above-mentioned parabola.

The interval of modification is usually contained within the interval of two pair tooth contact [2], since longer tip reliefs will produce higher QSTE but not better load sharing, as the load along the interval of single pair tooth contact will be equally the total load. However, such a long tip reliefs may be suitable for high contact ratio (HCR) spur gears, in which contact between involute profile points in at least one pair of teeth is guaranteed at any moment.

For long tip relief at the driven tooth tip of HCR spur gear, while a couple of teeth meshes at the extended contact interval at the outer limit, with the parabolic unloading process in progress, other couple is in mesh inside the modified contact interval. It has been proven that the load decreases considerably at the beginning of the contact interval (along the whole interval of profile modification), although it increases at the end of the contact interval (the outer interval of three pair tooth contact and the extended, parabolic-unloading contact interval). In addition, a peak of load may arise at the inner limit of the outer interval of two pair tooth contact, increasing the maximum transmitted load [2].

For HCR spur gears, the critical contact stress is always located at the beginning of the contact interval [10], while the critical tooth-root stress corresponds to contact somewhere inside the outer interval of two pair tooth contact [11]. Accordingly, with long tip relief at the driven tooth tip, the determinant contact stress will be smaller, though the determinant tooth-root stress may be greater, which means that long tip relief can be used for balancing the determinant stresses and improving the load capacity of the spur gear transmission.

This paper presents an investigation on the application of long tip relief to balance the contact and tooth-root stresses of HCR spur gears. An example illustrating the improvement on the load capacity by suitable long tip reliefs, is also provided. 
Fig. 1 Actual start of contact of a loaded tooth
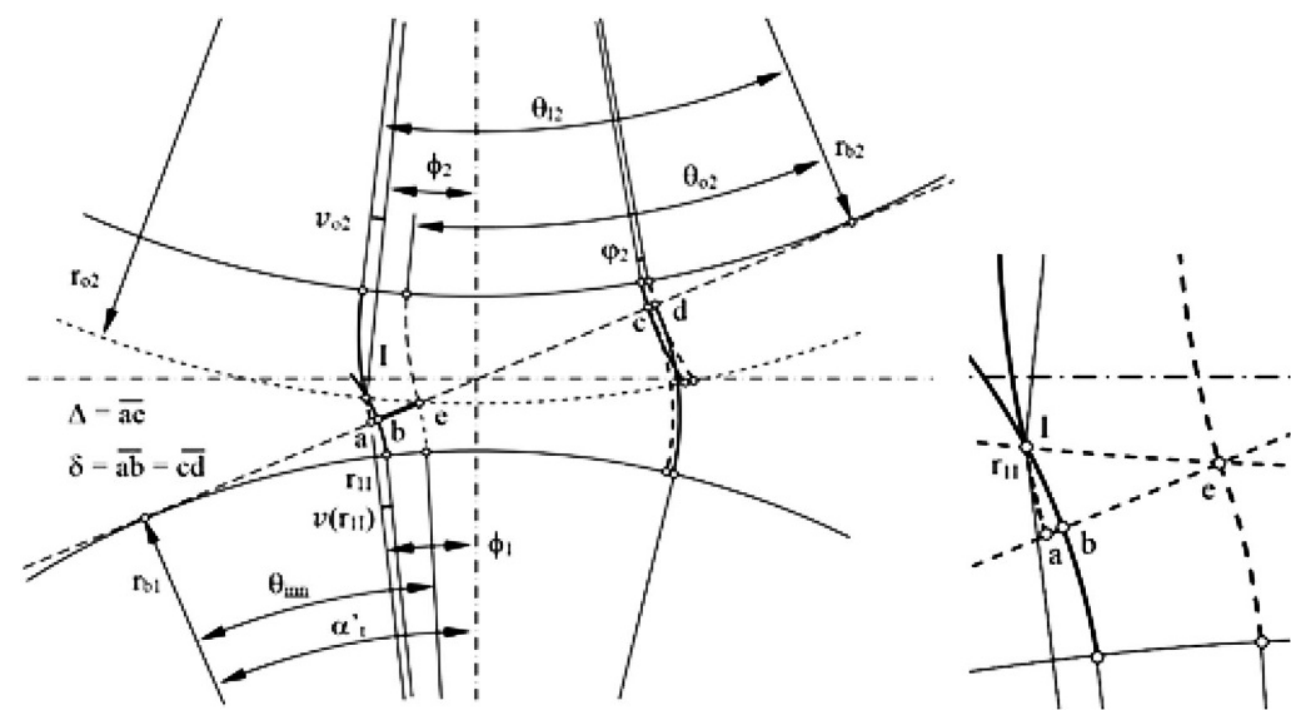

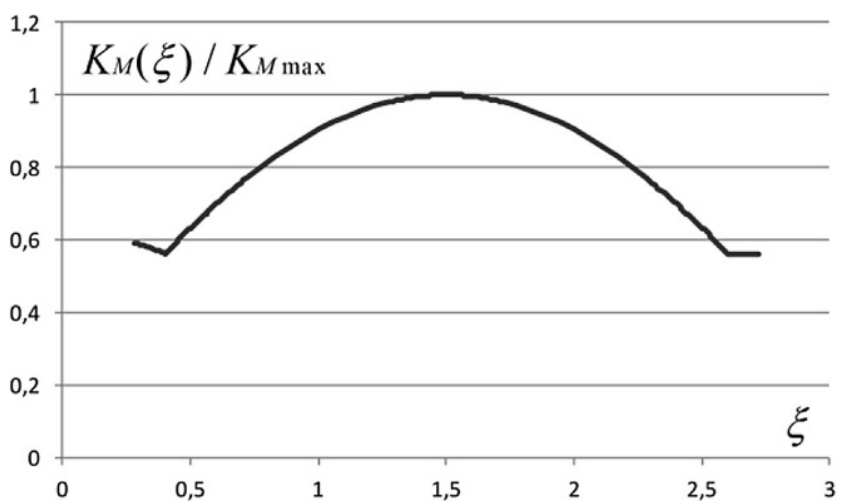

Fig. 2 Meshing stiffness along the extended interval of contact $\left(\varepsilon_{\alpha}=2.20\right)$

\section{Mesh stiffness and LSR of spur gear teeth}

The teeth deflections under load induce a delay of the driven gear respect to the driving one which results in an earlier start of contact, below the theoretical inner point of contact, and a delayed end of contact, beyond the theoretical outer point of contact. Fig. 1 shows the delay between the driving gear and the driven gear, which is described by the angle $\varphi_{2}$. Distance $a b$ in the line of action, which is equal to distance $c d$, represents the tooth pair deflection inducing the delay $\varphi_{2}$. Due to this relative rotation between both gears, the driving tooth root hits the driven tooth tip at point $I$ in the figure, before reaching the theoretical inner point of contact (point $e$ ). This earlier contact produces an additional contact interval, which is described by the interval be in Fig. 1 . A similar additional contact interval occurs at the end of contact (not represented in Fig. 1).

The curve of meshing stiffness along this extended contact interval is shown in Fig. 2. Within the theoretical con- tact interval, the curve of meshing stiffness of the tooth pair is accurately described by [12]:

$$
K_{M}(\xi)=K_{M \max } \cos \left(b_{0}\left(\xi-\xi_{m}\right)\right)
$$

with:

$b_{0}=\left[\frac{1}{2}\left(1.11+\frac{\varepsilon_{\alpha}}{2}\right)^{2}-1.17\right]^{-1 / 2} ; \quad \xi_{m}=\xi_{\text {inn }}+\frac{\varepsilon_{\alpha}}{2}$

where $\varepsilon_{\alpha}$ is the contact ratio and $\xi_{\text {inn }}$ and $\xi_{m}$ the driving tooth profile parameter $\xi$ corresponding to the inner point and the midpoint of the theoretical interval of contact, being $\xi$ :

$\xi=\frac{z_{1}}{2 \pi} \sqrt{\frac{r_{c 1}^{2}}{r_{b 1}^{2}}-1}$

in which $z$ is the number of teeth, $r_{c}$ the radius of the contact point, $r_{b}$ the base radius and subscript 1 denotes the driving gear (subscript 2 will denote the driven gear). Along the extended contact intervals, the meshing stiffness can be approximated to its value at the corresponding limit of the theoretical contact interval. Consequently, the meshing stiffness along the whole interval of contact can be expressed as:

$$
\begin{gathered}
K_{M}(\xi)=K_{M \text { max }} \cos \left(b_{0} \frac{\varepsilon_{\alpha}}{2}\right) \\
\xi_{\text {min }} \leq \xi \leq \xi_{\text {inn }} \\
K_{M}(\xi)=K_{M_{\text {max }}} \cos \left(b_{0}\left(\xi-\xi_{m}\right)\right) \\
\xi_{\text {inn }} \leq \xi \leq \xi_{\text {inn }}+\varepsilon_{\alpha} \\
K_{M}(\xi)=K_{M \text { max }} \cos \left(b_{0} \frac{\varepsilon_{\alpha}}{2}\right) \\
\xi_{\text {inn }}+\varepsilon_{\alpha} \leq \xi \leq \xi_{\text {max }}
\end{gathered}
$$



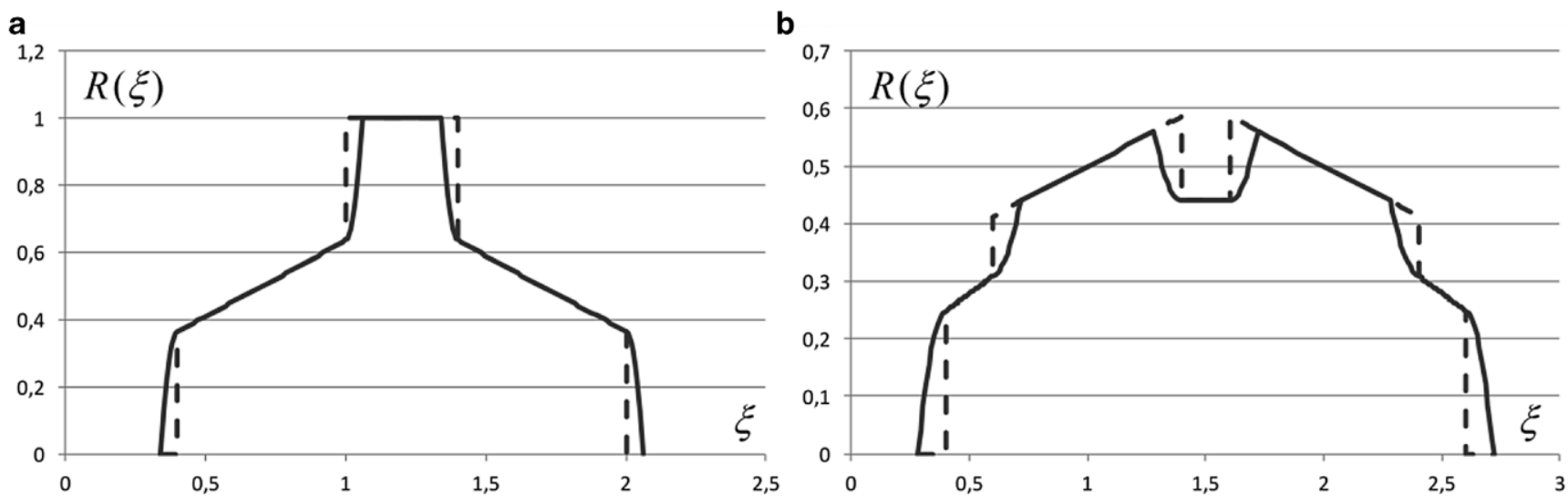

Fig. 3 Curves of LSR along the extended interval of contact. a Standard contact ratio $\left(\varepsilon_{\alpha}=1.60\right)$. b High contact ratio $\left(\varepsilon_{\alpha}=2.20\right)$

$\xi_{\min }$ and $\xi_{\max }$ denotes the profile parameter of the limits of the actual, extended interval of contact. Their values can be computed as described in [2, 3].

From this equation for the meshing stiffness, the load at tooth pair $i$ will be $[2,3]$ :

$$
F_{i}(\xi)=K_{M i}(\xi)\left(\delta(\xi)-\delta_{G i}(\xi)\right)
$$

where $\delta(\xi)$ is the delay of the driven gear in the path of contact (i.e., the QSTE multiplied by the base radius $r_{b 2}$ ) and $\delta_{G}(\xi)$ the distance that the driving tooth should approach to the driven one to contact it within the extended intervals, which can be calculated as:

$$
\begin{aligned}
\delta_{G}(\xi) & =C_{p} r_{b 1}\left(\frac{2 \pi}{z_{1}}\right)^{2}\left(\xi-\xi_{\text {min }}\right)^{2} \\
\xi_{\min } & \leq \xi \leq \xi_{\text {inn }} \\
\delta_{G}(\xi) & =0 \\
\xi_{\text {inn }} & \leq \xi \leq \xi_{\text {inn }}+\varepsilon_{\alpha} \\
\delta_{G}(\xi) & =C_{p}^{\prime} r_{b 1}\left(\frac{2 \pi}{z_{1}}\right)^{2}\left(\xi_{\max }-\xi\right)^{2} \\
\xi_{\text {inn }} & +\varepsilon_{\alpha} \leq \xi \leq \xi_{\max }
\end{aligned}
$$

where coefficients $C_{p}$ and $C^{\prime}{ }_{p}$ are calculated as described in [2]. The total load will be equal to the sum of the load at any tooth pair, so that, from Eq. 5:

$$
\begin{aligned}
F_{T} & =\sum_{j} F_{j}(\xi)=\sum_{j} K_{M j}(\xi)\left(\delta(\xi)-\delta_{G j}(\xi)\right) \\
& =\delta(\xi) \sum_{j} K_{M j}(\xi)-\sum_{j} K_{M j}(\xi) \delta_{G j}(\xi)
\end{aligned}
$$

and consequently:

$\delta(\xi)=\frac{F_{T}+\sum_{j} K_{M j}(\xi) \delta_{G j}(\xi)}{\sum_{j} K_{M j}(\xi)}$ which represents the delay of the driven gear and therefore describes the QSTE. Replacing Eq. 8 in Eq. 5, after some calculations, the following expression for the LSR is obtained:

$$
\begin{aligned}
& R_{i}(\xi)=\frac{F_{i}(\xi)}{F_{T}}=\frac{K_{M i}(\xi)}{\sum_{j} K_{M j}(\xi)} \\
& {\left[1+\frac{\sum_{j} K_{M j}(\xi)\left[\delta_{G j}(\xi)-\delta_{G i}(\xi)\right]}{F_{T}}\right]}
\end{aligned}
$$

Fig. 3 represents the LSR curves for standard and HCR spur gears. Dashed lines represent the theoretical LSR, which are valid for weakly loaded teeth.

\section{Tip relief on driven gear teeth}

A tip relief on the driven tooth can be expressed in terms of the $\xi$-parameter of the contact interval as:

$\delta_{R}=\delta_{R}(\xi)$ for $\xi \leq \xi_{\text {inn }}+\Delta \xi_{r}$

$\delta_{R}(\xi)=0$ for $\xi \geq \xi_{\text {inn }}+\Delta \xi_{r}$

where $\Delta \xi_{r}$ is the length of relief and function $\delta_{R}(\xi)$ defines the shape of relief. Obviously, to shift the start of contact to the theoretical inner point of contact $\xi_{\text {inn }}$ the amount of relief (i.e., the relief at the driven tooth tip $\xi_{o 2}$ ) should be equal to the teeth deflection at $\xi_{\text {inn }}$, so that:

$\delta_{R}\left(\xi_{\text {inn }}\right)=\delta\left(\xi_{\text {inn }}\right)$

which can be computed with Eq. 8. Fig. 4 shows the geometrical parameters of the tip relief. The load at the tooth pair $i$ is given by:

$F_{i}(\xi)=K_{M i}(\xi)\left(\delta(\xi)-\delta_{G i}(\xi)-\delta_{R i}(\xi)\right)$ 


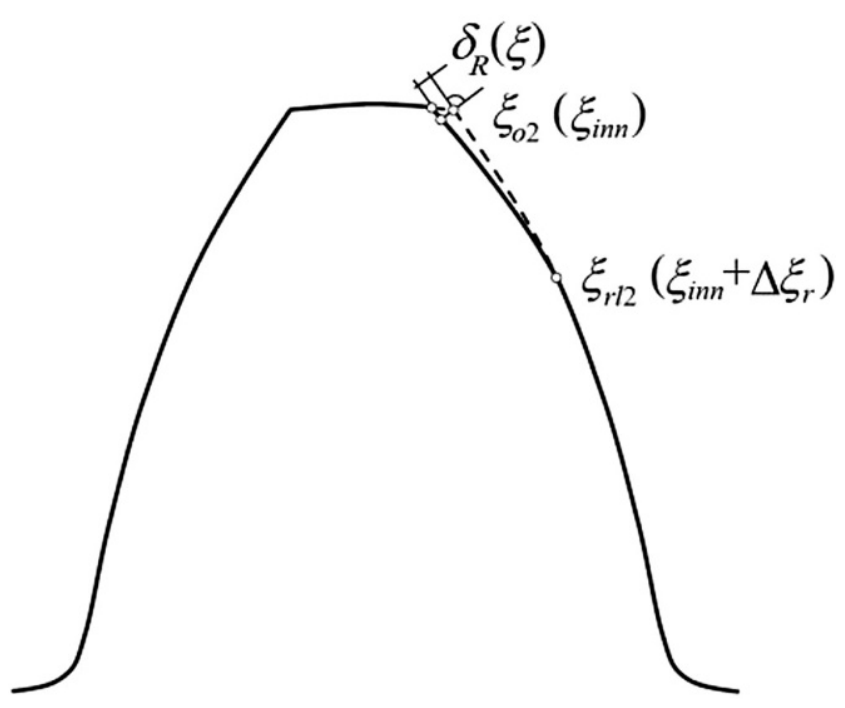

Fig. 4 Tip relief

and accordingly:

$$
\begin{aligned}
& F_{T}=\sum_{j} F_{j}(\xi)=\delta(\xi) \sum_{j} K_{M j}(\xi) \\
& -\sum_{j} K_{M j}(\xi)\left[\delta_{G j}(\xi)+\delta_{R j}(\xi)\right] \\
& \delta(\xi)=\frac{F_{T}+\sum_{j} K_{M j}(\xi)\left[\delta_{G j}(\xi)+\delta_{R j}(\xi)\right]}{\sum_{j} K_{M j}(\xi)} \\
& R_{i}(\xi)=\frac{K_{M i}(\xi)}{\sum_{j} K_{M j}(\xi)} \\
& {\left[1+\frac{\sum_{j} K_{M j}(\xi)\left[\left(\delta_{G j}(\xi)+\delta_{R j}(\xi)\right)-\left(\delta_{G i}(\xi)+\delta_{R i}(\xi)\right)\right]}{F_{T}}\right]}
\end{aligned}
$$

Note that:

$$
\left[F_{i}, K_{M i}, \delta_{G i}, \delta_{R i}\right](\xi)=\left[F, K_{M}, \delta_{G}, \delta_{R}\right](\xi+i)
$$

Fig. 5 represents the theoretical LSR curves, regardless parabolic unloading process, for HCR spur gear with linear tip relief at the driven tooth tip. Dashed lines represent the theoretical curves without relief. Diagram in Fig. 5a correspond to a tip relief with length of relief smaller than the fractional part of the contact ratio $d_{\alpha}$ (hence forward, short tip relief); Fig. 5b represents a tip relief longer than $d_{\alpha}$ (long tip relief). As expectable, along the interval of modification, the load on relieved teeth decreases, and consequently the load on pairs in simultaneous contact increases.

It can be observed that, for long tip relief, a peak of load arises at the inner limit of the outer interval of two pair tooth contact. This is because the load decreases at the inner limit of the other two pair contact interval, due to the relief. This means an increase in the maximum load, which may be undesirable from the strength point of view.
In fact, the critical tooth-root stress on HCR spur gears corresponds to contact somewhere inside this outer two pair contact interval [11]. However, the critical contact stress is often located at the inner points of the inner two pair contact interval. Consequently, long tip reliefs improve the surface strength but worsen the tooth-root strength. Since the surface strength is usually more restrictive than the tooth-root strength, the length of relieve could be used for balancing the power capacity from both points of view.

On the other hand, Fig. 5 represents the theoretical LSR of tip relieved HCR spur gears, but the actual curves will be affected by the parabolic unloading at the outer limit of the contact interval. In fact, Fig. $3 b$ suggests that the undesirable peak of load will be sensibly mitigated and its effects rather less dangerous. Fig. 6 shows the actual LSR for long tip relief. The peak of load is drastically reduced for not excessively long tip relieve (Fig. 6a), even eliminated if the length of modification is adjusted to the length of the three pair tooth contact interval (equal to $d_{\alpha}$ ) plus the length of the additional contact interval at the end of contact $\Delta \xi_{\max }$ (equal to $\xi_{\max }-\xi_{\text {inn }}-\varepsilon_{\alpha}$ ).

\section{Influence on stresses and load capacity}

According to [10], the critical contact stress is located at one of these points:

- the inner point of contact, $\xi_{\text {inn }}$ (point A in Fig. 7a).

- the inner point of the inner interval of two pair tooth contact, $\xi_{\text {inn }}+d_{\alpha}$ (point B).

- the outer point of the inner interval of two pair tooth contact, $\xi_{\text {inn }}+1$ (point C).

The equivalent curvature radius increases rapidly as the parameter $\xi$ decreases, and therefore, the lower the values of the parameter $\xi$ of the contact interval, the inner the point of critical contact stress. Consequently, the critical stress at point $\mathrm{C}$ will only occur for low gear ratio and high number of teeth on pinion. For these cases, the tip relief will not improve the surface strength. Critical stress is typically located at the inner point of contact (point A) for low number of teeth on pinion and high contact ratio, and will be always improved with tip relief, short reliefs even. Long tip reliefs may improve pitting load capacity for critical contact stress at point $\mathrm{B}$, which occurs for intermediate values of the pinion tooth number and contact ratio [10]. Fig. 7a presents the evolution of the contact stress along the path of contact for critical contact stress at point B.

The critical tooth-root stress does always correspond to contact at a point within the outer interval of two pair tooth contact [11] (interval D-E in Fig. 7b). Although this critical load point may be located at any point of that interval, the tooth-root stress is quite uniform along it, as represented 

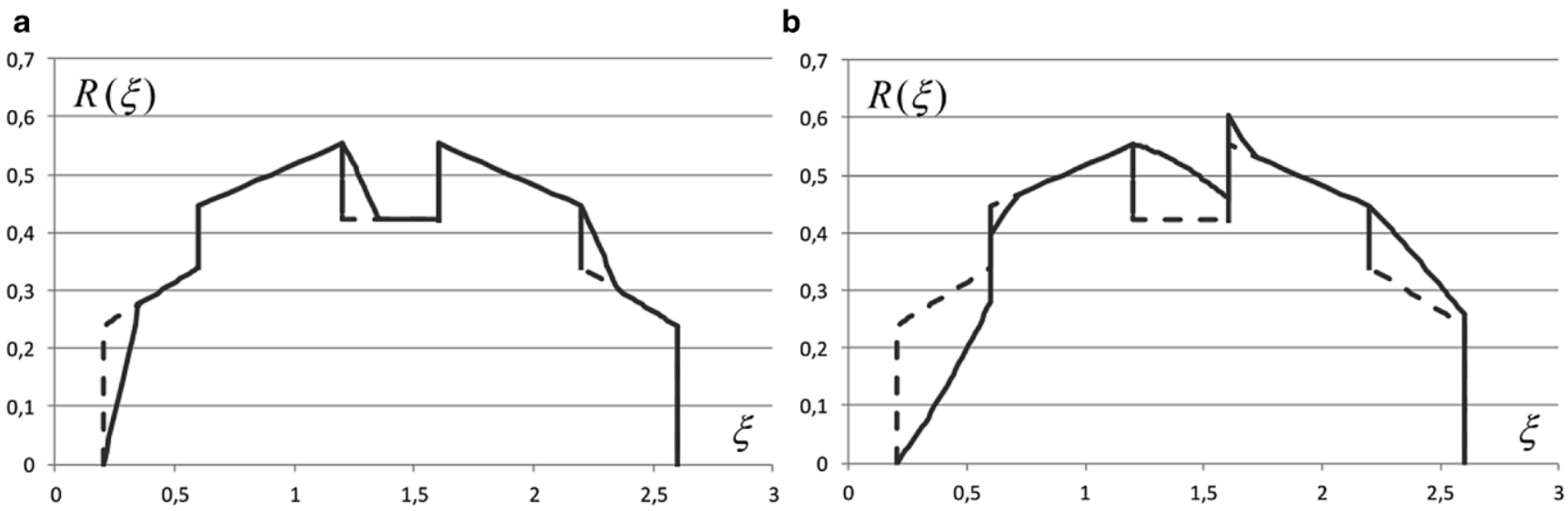

Fig. 5 Theoretical curves of LSR for short and long tip relief $\left(\varepsilon_{\alpha}=2.40\right)$. a Short tip relief $\left(\Delta \xi_{r}=0.15\right)$. b Long tip relief $\left(\Delta \xi_{r}=0.50\right)$
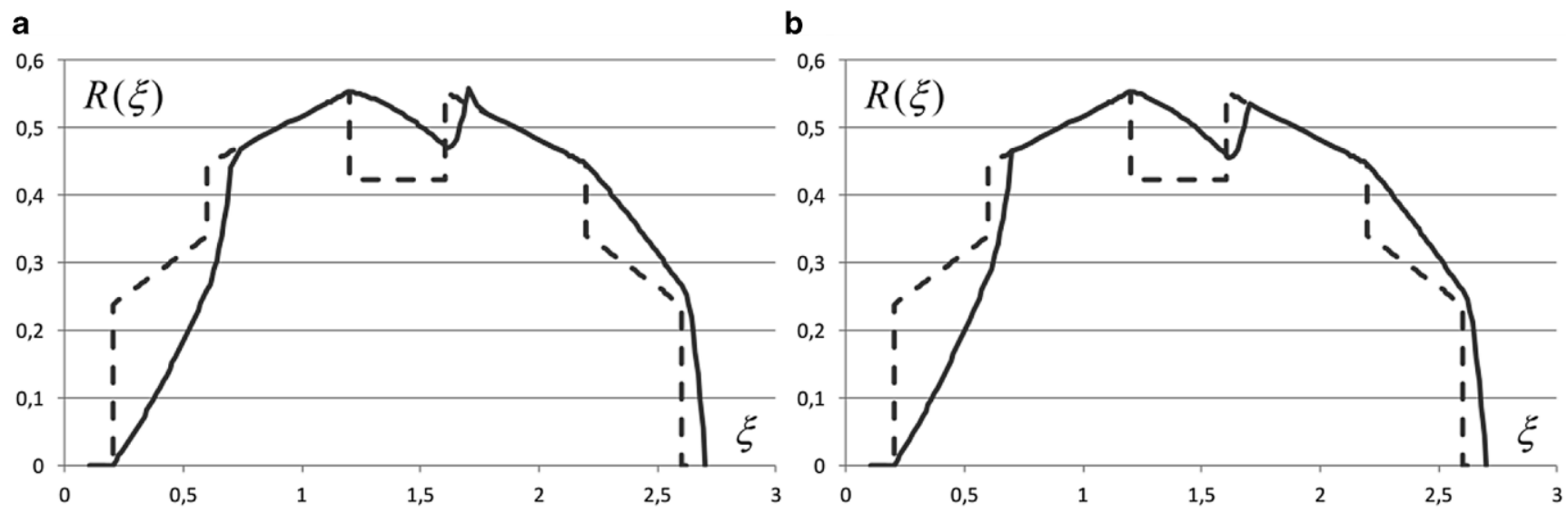

Fig. 6 Actual LSR for HCR spur gears with long tip relief $\left(\varepsilon_{\alpha}=2.40, \Delta \xi_{\max }=0.10\right)$. a Long tip relief $\left(\Delta \xi_{r}=0.55\right)$. b Adjusted length of relief $\left(\Delta \xi_{r}=0.50\right)$

in Fig. 7b. The critical stress will therefore correspond, for long tip relief, to the peak of load, which is always located at $\xi=\xi_{\max }-1$. In addition, the relation between critical toothroot stresses for long tip relief and no tip relief will be very close to the relation between the peak of load and the load at this point without relief.

From Fig. 6a, b and 7a, for long tip relief the critical contact stress will occur well at the upper limit of the interval of modification $\xi=\xi_{\text {inn }}+\Delta \xi_{\text {r }}$, well at the peak of load $\xi=\xi_{\max }-1$. The relation between critical stresses for long tip relief and no tip relief will be equal to the relation between corresponding $\Phi$ parameters:

$\Phi(\xi)=\sqrt{\frac{R(\xi)}{\xi\left(\lambda_{\xi}-\xi\right)}}$ with $\lambda_{\xi}=\frac{z_{1}+z_{2}}{2 \pi} \tan \alpha_{t}^{\prime}$

where $\alpha^{\prime}{ }_{t}$ is the operating pressure angle. Summarizing, if $R_{R}(\xi)$ denotes the load sharing ratio for tip relief and $\Phi_{R}(\xi)$ the $\Phi(\xi)$ parameter computed with $R_{R}(\xi)$, the ratio between bending load capacities for long tip relief $P_{F R}$ and no tip relief $P_{F}$, will be given by:

$\frac{P_{F R}}{P_{F}}=\left[\frac{R\left(\xi_{\max }-1\right)}{R_{R}\left(\xi_{\max }-1\right)}\right]$

while the ratio between pitting load capacities with and without relief, $P_{H R}$ and $P_{H}$, is given by:

$$
\frac{P_{H R}}{P_{H}}=\left[\frac{\Phi\left(\xi_{\text {inn }}+d_{\alpha}\right)}{\max \left[\Phi_{R}\left(\xi_{\text {inn }}+\Delta \xi_{r}\right), \Phi_{R}\left(\xi_{\max }-1\right)\right]}\right]^{2}
$$

\section{Example}

The following spur gear pair will be considered: number of teeth on pinion and wheel 39 and 78 , module $5 \mathrm{~mm}$, pressure angle $14^{\circ}$, rack shift coefficient on both gears 0 , tooth addendum $5 \mathrm{~mm}$, tooth dedendum $6.25 \mathrm{~mm}$, tool tip radius $1.25 \mathrm{~mm}$, operating center distance $292.5 \mathrm{~mm}$. For this geometry, the value of $\lambda_{\xi}$ is 4.643 , the contact ratio 
Fig. 7 Evolution of the stresses along the path of contact for no tip relief. a Contact stress. b Tooth-root stress
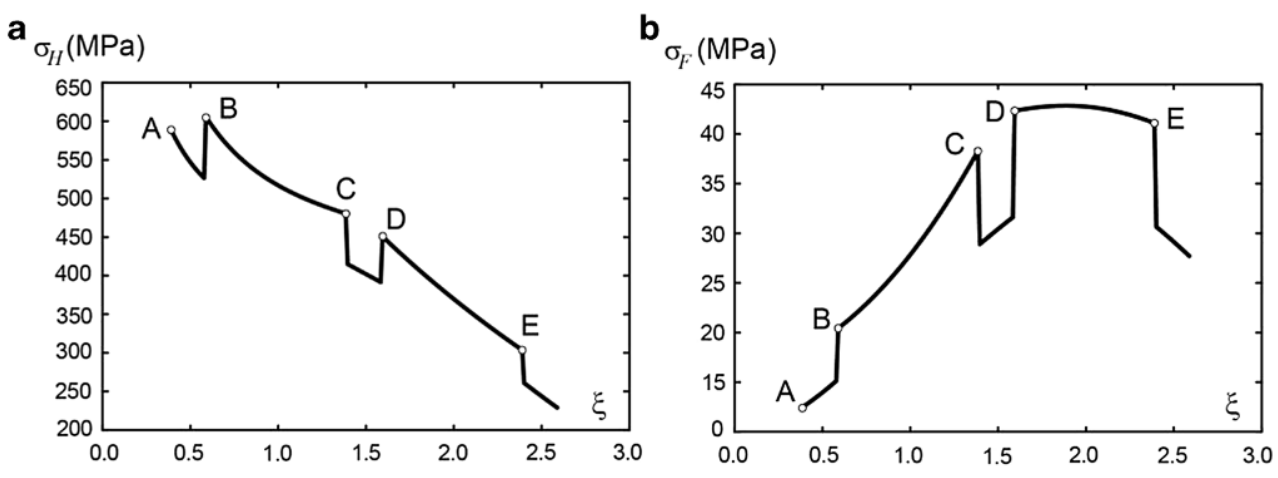

a

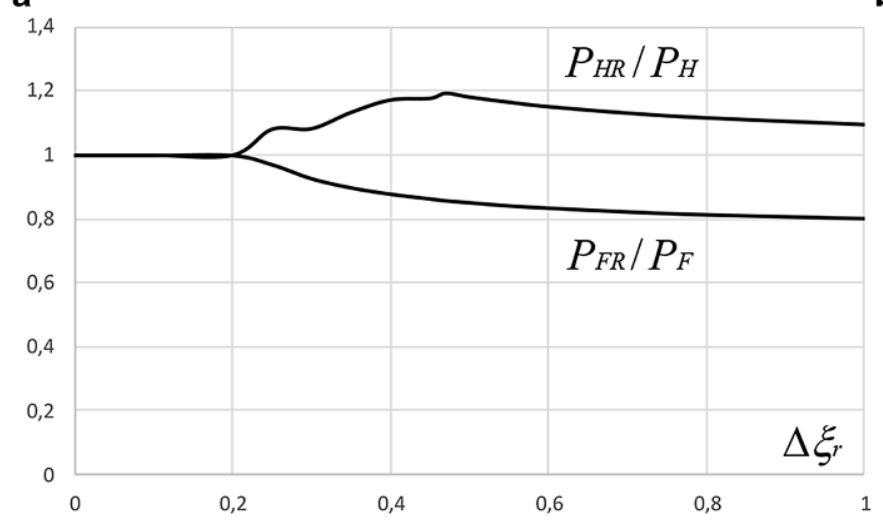

b

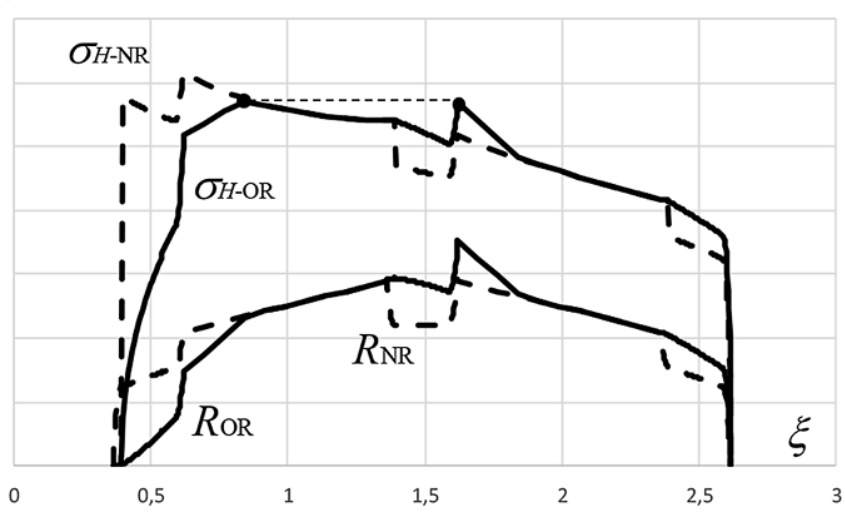

Fig. 8 Results of the considered example. a Evolution of the load capacities with the length of modification. b Evolution of LSR and contact stress for no relief (NR) and optimal relief (OR)

is $\varepsilon_{\alpha}=2.198$ and the inner point of contact is described by $\xi_{\text {inn }}=0.390$. The material is steel C45. The output torque of $318.31 \mathrm{~N} \cdot \mathrm{m}$ induces an additional interval of contact at the end of meshing of $\Delta \xi=0.03$, and therefore $\xi_{\max }=2.618$. An analysis according to ISO 6336 for $900 \mathrm{rpm}$ input velocity, reveals power capacities of 72.795 and $15.765 \mathrm{~kW}$ for bending and pitting, respectively.

Fig. 8a presents the variation of bending and pitting load capacities, for different values of the length of relief $\Delta \xi_{r}$ between 0.0 and 1.0. Some conclusions can be drawn:

- For tip relief shorter than $d_{\alpha}+\Delta \xi(0.228$ in this example), both load capacities for bending and pitting remain unalterable.

- For longer reliefs, the bending load capacity decreases with the length of relief, while the pitting load capacity increases up to a maximum (for $\Delta \xi_{r}=0.47$ in the example) and decreases from it. This maximum is due to the contact stress at the peak of load becomes determinant, as shown in Fig. 8b.

In this example, the pitting load capacity can be increased up to $19.4 \%$, though the bending load capacity will decrease by $14.3 \%$. Since the last one remains greater than the other, the final load capacity will increase by $19.4 \%$.

\section{Conclusions}

Long tip reliefs in HCR spur gears, beyond the inner interval of three pair tooth contact, produces lower loads at the inner points on the contact interval, resulting in many cases in a decrease on the determinant contact stress. However, a peak of load may arise at the outer interval of two pair tooth contact, which results in an increase on the determinant tooth-root stress. Thus, for the not unusual cases in which calculated load carrying capacity for bending is greater than that for pitting, long tip relief could be used for balancing pitting and bending load capacities, which allows to improve the final load capacity of the gear pair.

Acknowledgements Our gratitude to the Spanish Council for Scientific and Technological Research for the support of the project DPI2015-69201-C2-1-R, "Load Distribution and Strength Calculation of Gears with Modified Geometry", as well as to the School of Engineering of UNED for the support of the action 2019-MEC24, "Simulation of transmission error in spur gears".

Open Access This article is distributed under the terms of the Creative Commons Attribution 4.0 International License (http:// creativecommons.org/licenses/by/4.0/), which permits unrestricted use, distribution, and reproduction in any medium, provided you give appropriate credit to the original author(s) and the source, provide a 
link to the Creative Commons license, and indicate if changes were made.

\section{References}

1. Gregory RW, Harris SL, Munro RG (2002) A method of measuring transmission error in spur gears of 1:1 ratio. J Sci Instrum. https:// doi.org/10.1088/0950-7671/40/1/303

2. Pedrero JI, Pleguezuelos M, Sánchez MB (2018) Control del error de transmisión cuasiestático mediante rebaje de punta en engranajes rectos de perfil de evolvente. Revista Iberoamericana De Ingeniería Mecánica 22:71-90

3. Pedrero JI, Pleguezuelos M, Sánchez MB (2017) Load sharing model for spur gears with tip relief. International Conference on Gears, Munich, Germany, 2017 (Proc.)

4. Tavakoli MS, Houser DR (1986) Optimum profile modifications for the minimization of static transmission errors of spur gears. J Mech Trans Autom. https://doi.org/10.1115/1.3260791

5. Lin HH, Oswald FB, Townsend DP (1994) Dynamic loading of spur gears with linear or parabolic tooth profile modifications. Mech Mach Theory. https://doi.org/10.1016/0094-114X(94)90003-5

6. Beghini M, Presicce F, Santus C (2004) A method to define profile modification of spur gear and minimize the transmission er- ror, AGMA Paper 04FTM3. American Gear Manufacturers Association, Alexandria VA

7. Wen Q, Du Q, Zhai X (2019) An analytical method for calculating the tooth surface contact stress of spur gears with tip relief. Int $\mathrm{J}$ Mech Sci. https://doi.org/10.1016/j.ijmecsci.2018.11.007

8. Velex P, Bruyere J, Houser DR (2011) Some analytical results on transmission errors in narrow-faced spur and helical gears: influence of profile modifications. J Mech Des. https://doi.org/10.1115/ 1.4003578

9. Ma H, Zeng J, Feng R, Pang X, Wen B (2016) An improved analytical method for mesh stiffness calculation of spur gears with tip relief. Mech Mach Theory. https://doi.org/10.1016/j. mechmachtheory.2015.11.017

10. Sánchez MB, Pedrero JI, Pleguezuelos M (2013) Contact stress calculation of high transverse contact ratio spur and helical gear teeth. Mech Mach Theory. https://doi.org/10.1016/j.mechmachtheory. 2013.01.013

11. Sánchez MB, Pleguezuelos M, Pedrero JI (2014) Tooth-root stress calculation of high transverse contact ratio spur and helical gears. Meccanica. https://doi.org/10.1007/s11012-013-9799-3

12. Sánchez MB, Pleguezuelos M, Pedrero JI (2017) Approximate equations for the meshing stiffness and the load sharing ratio of spur gears including hertzian effects. Mech Mach Theory. https:// doi.org/10.1016/j.mechmachtheory.2016.11.014 